US Army Corps of Engineers ${ }_{\circledast}$

\section{Fine-Grained Sediment within Olcott Harbor, Eighteenmile Creek, NY}

Heidi M. Wadman

PURPOSE: Olcott Harbor, located at the mouth of Eighteenmile Creek and Lake Ontario, and a Great Lake Area of Concern, provides a temporary sink for contaminated, fine-grained sediment transported downstream from the Superfund site near Lockport, NY. The volume of fine-grained sediment currently stored in Olcott Harbor and Eighteenmile Creek is unknown, complicating remediation efforts. The US Army Corps of Engineers (USACE), Buffalo District (LRB), has partnered with the New York State Department of Environmental Conservation to address the mitigation of contaminated sediment accumulating within Eighteenmile Creek. As part of this effort, researchers from the US Army Engineer Research and Development Center (ERDC) collaborated with LRB to delineate fine-grained sediment regions from coarse-grained regions in Olcott Harbor and Eighteenmile Creek via a geophysical survey in July 2017. Where possible, ERDC also estimated the thickness of the fine-grained sediment areas to determine overall finesediment volume. Sidescan sonar was used to map the surface transition from the coarser-grained sediment in the outer harbor to the finer-grained sediment in the inner harbor. Chirp sub-bottom profiles successfully imaged the subsurface transition from coarse- to fine-grained sediment in some areas but provided only limited thickness data. This technical note summarizes the field effort, data processing, and final interpretations.

STUDY AREA: Olcott Harbor is a small harbor ( 12 acres) ${ }^{*}$ located where Eighteenmile Creek meets Lake Ontario along the northern border of New York State (Figure 1). Conditions in the inner harbor are generally calm, though large swells from Lake Ontario can generate chop in the outer harbor (significant wave heights of 1-2 $\mathrm{ft}^{\dagger}$, with short periods of 2-4 s) that can be reflected into the inner harbor. The northern boundary includes the entrance channel into Lake Ontario, and the southern boundary is adjacent to NY St. Route 18.

METHODOLOGY: The geophysical survey was conducted by ERDC on Tuesday, July 25, 2017. Due to the unavailability of the LRB survey vessel, engineers from the USACE Detroit District (LRE) Hydrology and Hydraulics Branch volunteered one of its vessels as well as a small operational crew to assist ERDC with the data collection. LRE also brought its geophysical survey equipment for ERDC to compare with the LRB equipment. The survey was completed as two efforts: a morning survey with the LRB geophysical equipment in the inner harbor and an afternoon survey with the LRE geophysical equipment in both the inner and outer harbor, including the entrance to the lake. Wave conditions precluded collecting data with the LRB equipment in the outer harbor during the morning survey. In addition to the survey data, seven surface sediment samples were collected with a petite ponar sediment sampler to help characterize the geophysical

\footnotetext{
${ }^{*}$ For a full list of the unit conversions used in this document, please refer to US Government Publishing Office Style Manual, 31st ed. (Washington, DC: US Government Publishing Office 2016), 345-7, https://www.govinfo.gov/content/pkg/GPO-STYLEMANUAL-2016/pdf/GPO-STYLEMANUAL-2016.pdf.

${ }^{\dagger}$ For a full list of the spelled-out forms of the units of measure used in this document, please refer to US Government Publishing Office Style Manual, 31st ed. (Washington, DC: US Government Publishing Office 2016), 248-52, https://www.govinfo.gov/content/pkg/GPO-STYLEMANUAL-2016/pdf/GPO-STYLEMANUAL-2016.pdf.
} 
data. For the purposes of this report, the term creek bed will refer to the sediment-water interface in both Eighteenmile Creek and Olcott Harbor.

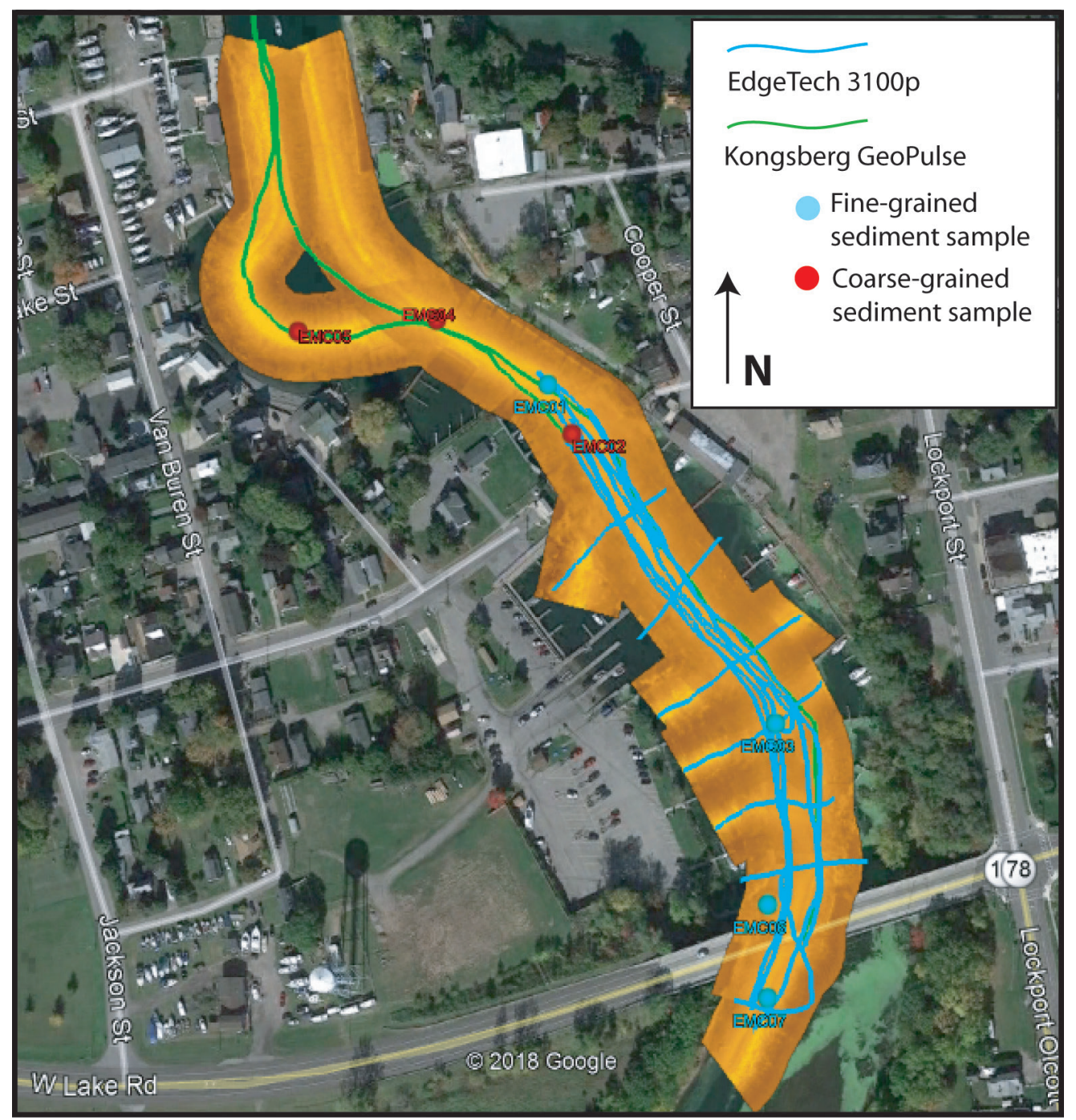

Figure 1. Location of Olcott Harbor along the coastline of Lake Ontario. The full extent of the sidescan mosaic is superimposed on the satellite image. Tracklines for the EdgeTech 3100p are shown in blue; tracklines for the Kongsberg are shown in green. Sediment cores are plotted as filled circles: blue for fine-grained, red for coarse-grained (size definitions provided in text).

From $\sim 0800$ to 1200,16 survey lines were collected using the LRB Tritech Starfish 990F sidescan sonar and EdgeTech 3100p chirp sub-bottom profiler, and the tracklines for both are shown in blue on Figure 1. The Tritech was pole mounted to the bow of the survey vessel approximately $50 \mathrm{~cm}$ below the water line, and the EdgeTech was towed along the starboard side of the vessel. Data were collected simultaneously. Differential Global Positioning System (GPS) was used for vessel positioning, and data were collected in NAD83 State Plan Coordinate System, New York West (ft US). The Starfish operates using a digital chirp digitally converted to a $1 \mathrm{MHz}$ acoustic signal, and all lines were collected at the same beam width. Sound speed of $1500 \mathrm{~m} / \mathrm{s}$ was used during 
collection. The EdgeTech sub-bottom profiler uses chirp acoustics to generate a range of pulses to reflect off of changes in sediment density below the creek bed, and specifics for the chirp pulse used on any given line are provided in the Appendix. Note that the term chirp with respect to subbottom profiling refers to the range of acoustic frequencies generated by the profiler and is not a similarly named, high-intensity, compressed radar pulse (CHIRP) sidescan sonar system. The EdgeTech is a self-contained sub-bottom profiler with the transducer (sound generator) and the receivers housed in the same towfish body. Gains were not applied on either raw data types during collection. All data were collected using Chesapeake Technology SonarWiz ver 6.05.0020.

From $\sim 1500$ to 1845 , six survey lines were collected using the LRE Kongsberg GeoPulse chirp sub-bottom profiler. Unlike the self-contained EdgeTech, the Kongsberg chirp towfish body only contains the system's transducer. The acoustic receivers are configured into four separate hydrophone cables that are designed to be streamed a minimum of $30 \mathrm{ft}$ behind the towfish. The confined space of the small survey area precluded streaming the hydrophones, and they instead had to be secured against the side of the vessel. Kongsberg chirp tracklines are plotted as green lines on Figure 1 and specifics for the chirp pulse used on any given line are provided in the Appendix. Gains were not applied on the raw sub-bottom data during collection. All data were collected using Chesapeake Technology SonarWiz ver. 6.05.0020.

Seven sediment samples were collected via a petit ponar grab sampler, and locations are shown on Figure 1. EMC-01, EMC-02, and EMC-03 were collected to groundtruth the LRB data, and EMC04, EMC-05, EMC-06, and EMC-07 were collected to groundtruth the LRE data. For each sample, the location of the grab as plotted in Figure 1 was determined by the vessel position when the petit ponar was on the creek bed itself during each sampling event.

Geophysical Data Processing. All data for this effort were processed and interpreted by ERDC. Details on the sidescan and subbottom components are provided in the relevant sections, below.

Sidescan Processing. Sidescan sonar data were imported into Chesapeake Technology SonarWiz Map ver. 6.05.0020 using a time constant for course smoothing of 300 pings. With a sonar frequency of $20 \mathrm{~Hz}$ and an average vessel speed of $\sim 1 \mathrm{knot}$, this translates to an average horizontal smoothing of $\sim 7 \mathrm{~m}$. No gain was applied during import. The outer $30 \%$ of the sidescan swath was trimmed on import to reduce data artifacts caused by errors in the far range of the amplitude data. Data were imported as normal polarity ensuring that higher (denser) amplitudes were plotted as the bright range of the total amplitudes.

The water column was automatically tracked using SonarWiz's Auto Tracking function set to the port transducer, and line-specific settings are noted in the Appendix. Where necessary, identification of the water column was user adjusted to remove incorrect identification (i.e., the auto tracker identifying the high amplitude return on a fish in the water column as the creek bed). Where submerged aquatic vegetation (SAV) growth was thick enough to obscure the creek bed, the sediment/water interface was estimated by the user (Figure 2). 


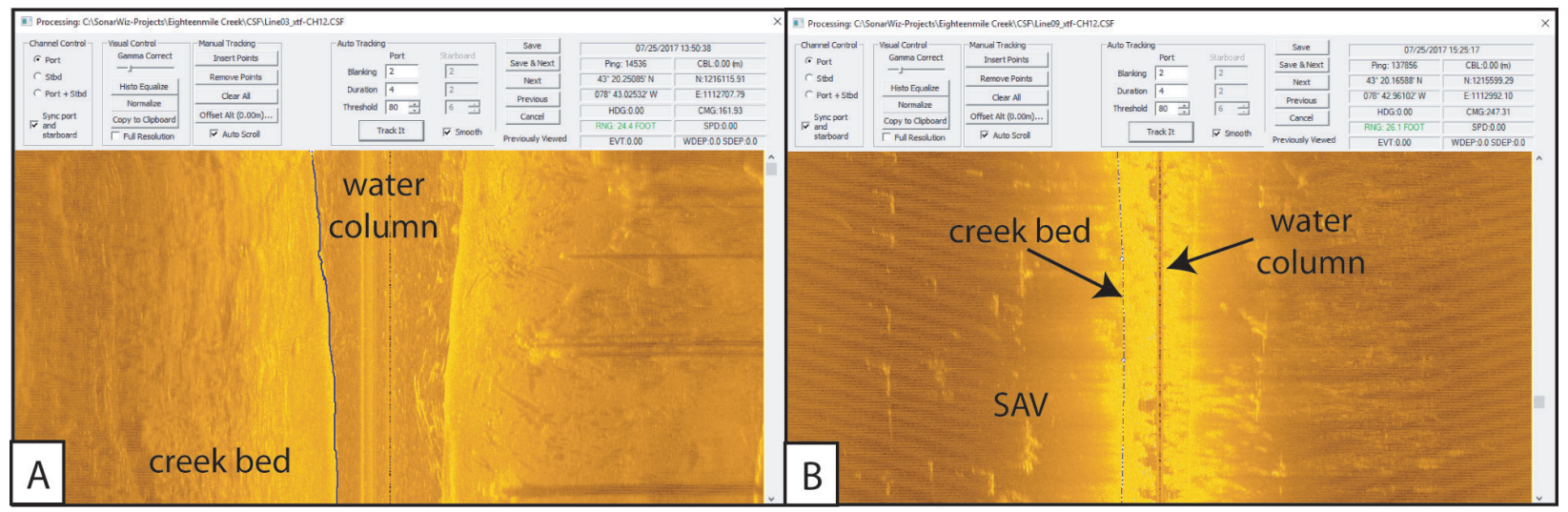

Figure 2. Example of water column identification in the sidescan data for regions both with and without SAV. (A) Region with no SAV and software-defined sediment/water interface. (B) Region with SAV growth obscuring the creek bed and a user-defined sediment/water interface.

After water column removal, the histogram for data visualization was hand adjusted using a standard beam angle correction to maximize resolution of the far-range data without losing the near-nadir data, allowing for a cleaner mosaic without the data smoothing that often results from the addition of user-defined gains. Overlapping sidescan data were averaged before generation of the final mosaic (Figure 1).

Chirp Sub-Bottom Processing. Chirp sub-bottom sonar data were imported into Chesapeake Technology SonarWiz ver. 6.05.0020. Several pulse frequencies and lengths were utilized during data collection, but overall, data recorded using a pulse frequency of $2.4-10 \mathrm{kHz}$ and length of $100 \mathrm{~ms}$ provided the best quality data, and only lines collected with those settings were processed. Only the upper $50 \%$ of the sub-bottom vertical record was imported as sound penetration, and reflection was limited to the upper $4 \mathrm{~m}$ of creek bed. The water column was automatically tracked using SonarWiz's AutoTracking function, and line-specific settings are noted in Table 2 in the Appendix. The water column was not removed, however, to preserve where SAV growing into the water column resulted in acoustic returns. Preservation of these water column data precluded the removal of the heave caused by wave action during collection, and thus heave is apparent in the final data record (Figure 3). Digitization of the creek bed, as well as any visible lower reflection surfaces, was conducted by one person to eliminate the discrepancies in the identification of the reflection elevation that can occur when more than one person interprets the sub-bottom record.

Sediment Processing. After collection, sediment samples were emptied into a stainless steel pan and identified in the field as dominantly sandy or muddy. The pan was rinsed with water between each sample to eliminate any cross-contamination of grainsize. In addition to the field descriptions, three of the samples were sent off to TTL Associates Inc. for Standard Test Method for Particle-Size Analysis of Soils (ASTM D 422). 


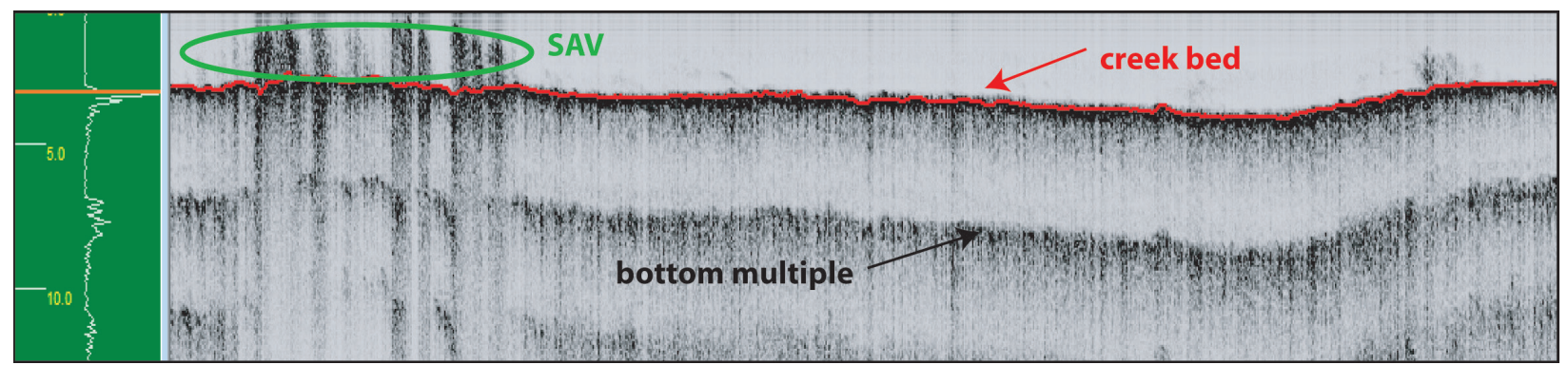

Figure 3. Example of water column identification in the chirp sub-bottom data for SAV.

Identification of Fine-Grained/SAV Regions. In the sidescan sonar data, coarse-grained sediment areas were defined qualitatively on the basis of higher (i.e., brighter) creek bed amplitudes, as well as the presence of debris standing proud on the creek bed and sedimentary features such as sand ripples and waves. In contrast, regions of less-dense sediment were defined on the basis of lower (darker) amplitudes, abundant SAV, and low-profile relief of any bed features, if any (Figure 4). The grainsize data were used to validate and further refine these interpretations. In the sidescan data, the contacts between fine-grained sediment, coarse-grained sediment, and SAV beds were digitized on each sidescan line, and the latitude and longitude of each digitized point was exported as a .csv file. These points were converted from SonarWiz proprietary format into $\mathrm{kml}$ files using a free online program: https://www.earthpoint.us/ExcelToKml.aspx and imported into Google Earth Pro ver. 7.3.1.4507. The points were digitized as areas in Google Earth, and the overall spatial extent of the fine-grained regions was calculated as acreage. The final area polygons were converted into area $\mathrm{kml}$ files and imported into Golden Software Surfer ver. 15.1.285 for final conversion to ESRI shapefiles.

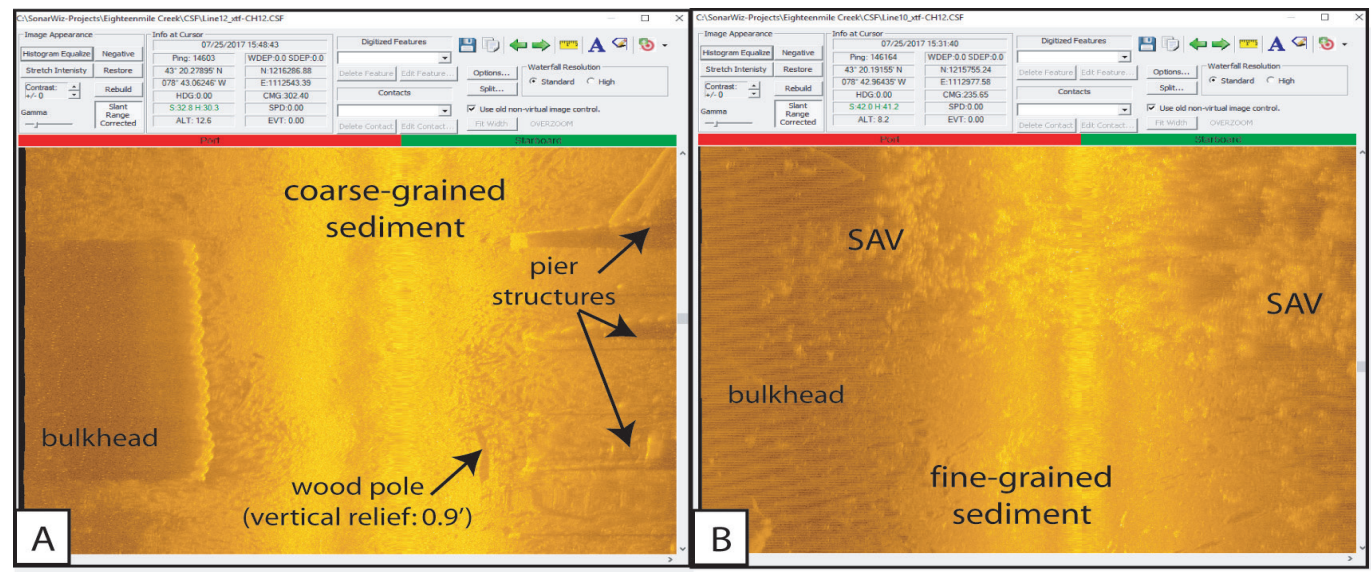

Figure 4. Examples of fine-grained and coarse-grained sediment areas as imaged by the sidescan sonar.

In the chirp sub-bottom data, coarse-grained sediment areas were defined qualitatively on the basis of the coarser, denser sediment resulting in higher acoustic impedance of the riverbed, which is imaged as bright white regions below the riverbed, with little or no underlying reflection surfaces. In contrast, finer-grained, less dense sediments are characterized by lower acoustic impedance, imaged as a darker gray, smudged sub-bottom record, with occasional lower reflection surfaces indicating changes in sediment density (stratigraphy) with depth (Figure 5). In addition, SAV mapped by the chirp was limited to regions also characterized by lower acoustic impedance, 
indicating that SAV growth was limited to the fine-grained regions. Images of all sub-bottom data are provided as supplemental information to this technical note.

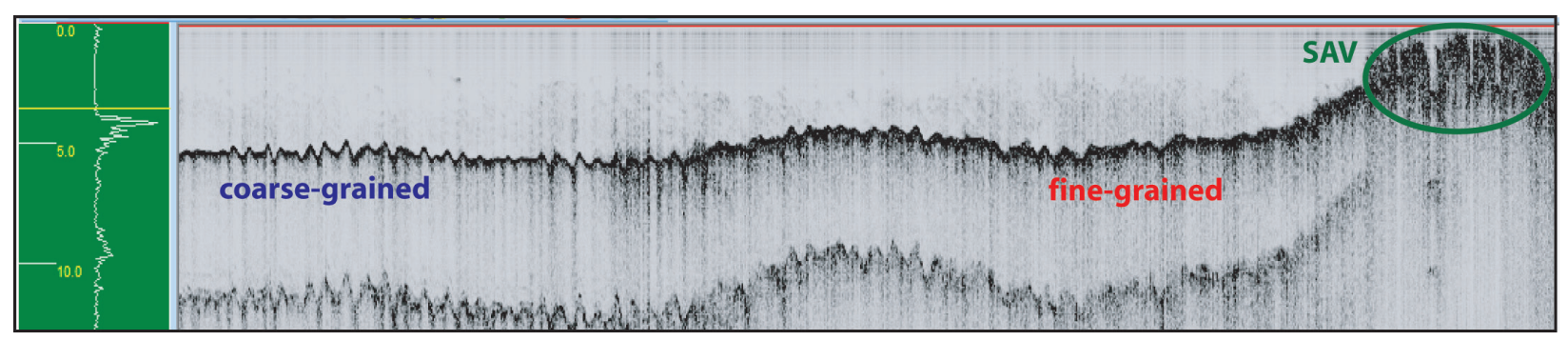

Figure 5. Examples of fine-grained and coarse-grained sediment areas as imaged by the chirp subbottom profiler.

RESULTS: Olcott Harbor is located at the confluence of Eighteenmile Creek to the south and Lake Ontario to the north (Figures 1,6). The outer harbor that includes the lake entrance runs from north to south approximately $850 \mathrm{ft}$. At that point, a small turning basin connects the outer harbor to the inner harbor oriented $\sim 70^{\circ}$ towards the southeast from the entrance channel. The surficial distribution of most of the fine-grained sediment and associated SAV growth was primarily limited to within the inner harbor, $\sim 260 \mathrm{ft}$ east of the turning basin (blue and green shaded areas, respectively, on Figure 6). Outside of this region, the sediment was coarse-grained sands and gravels (red shaded region on Figure 6). A small patch of coarse-grained sediment was found between the turning basin within the inner harbor fine-grained region (Figure 6).

Mapping the inner harbor was limited by the multiple finger piers extending into the harbor, and those data limitations are illustrated in Figure 7. The sidescan data appear to overlap the finger piers where vessels are moored (Figure 7a). This is due to the decision not to crop out more than $30 \%$ of the sidescan swath to maintain full data coverage where possible. The green and blue shaded regions digitized on the mosaic (Figure $7 b$ ) show the extent of reliable data interpretations, though it is likely that fine-grained sediment is located beneath the piers as well.

SAV growth was restricted to along the edges of the harbor, including between the finger docks on the western bank. The very center of the creek had significantly less SAV growth, or it was absent altogether. South of the bridge on West Lake Rd (Rt. 18), SAV was extensive in the center of the creek and along the eastern edge but was scarce along the western edge. The entire surface sediment south of the bridge was fine grained in nature. 


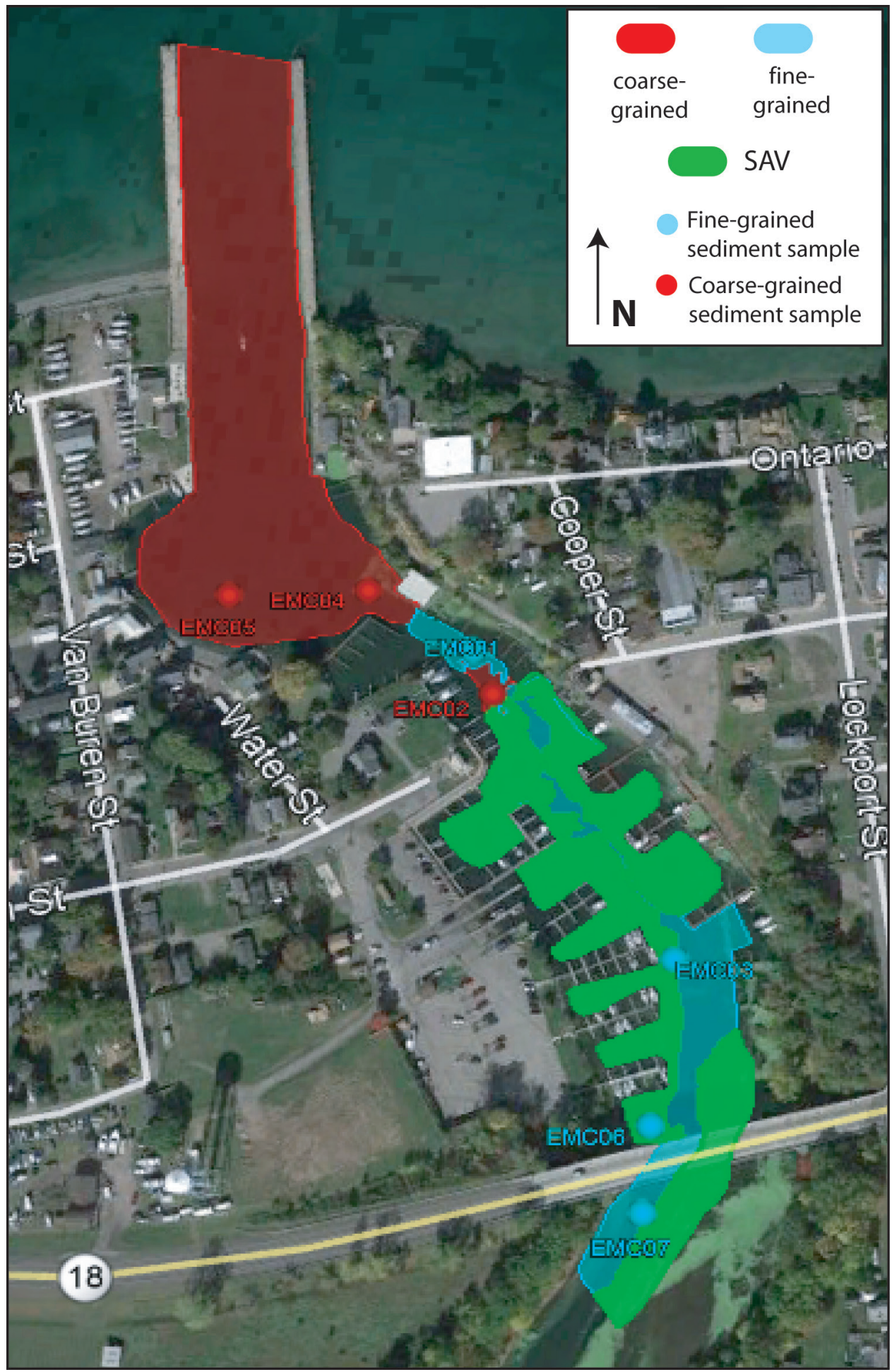

Figure 6. Spatial distribution of coarse- and fine-grained regions in Oloctt Harbor and Eighteenmile Creek. Red-shaded areas represent coarse-grained areas, blue-shaded areas represent fine-grained areas, and green-shaded areas represent regions where SAV was thick enough to obscure the surface sediment. Sediment samples were previously shown on Figure 1 and are replotted here for ease in interpretation. 


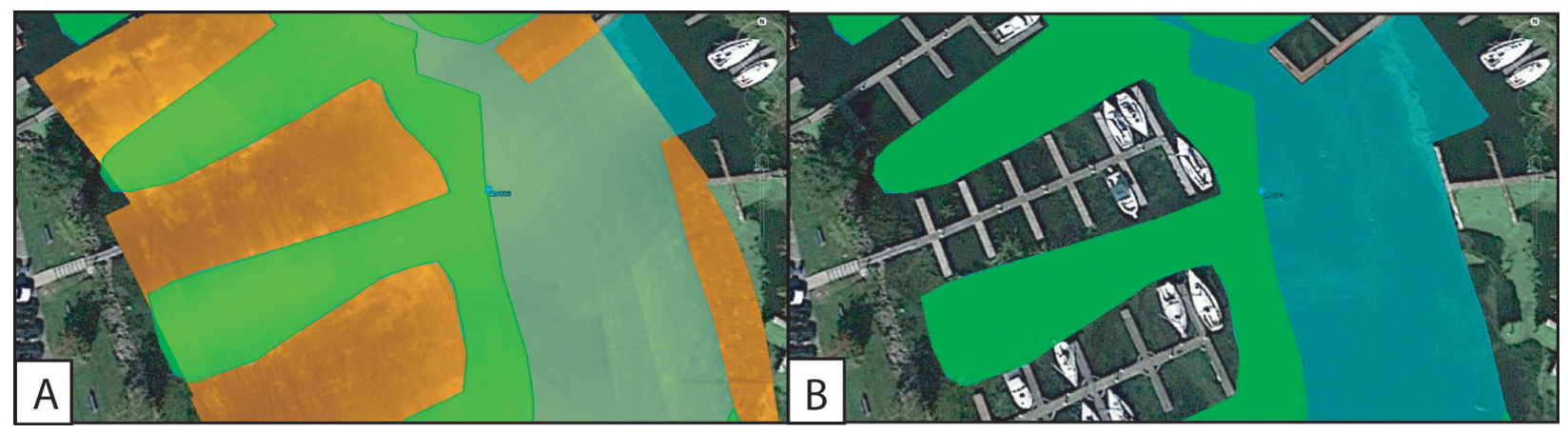

Figure 7. Close-up of the sidescan mosaic showing: (A) sidescan overlap obscuring the finger piers and (B) reliable, mapped extent of fine-grained and/or SAV regions between the finger piers.

Of the 16 EdgeTech chirp lines collected, 14 contained suitable data. The other two lines were too short to be useful. Details on line import and digitization status are provided in the Appendix. The surface return of the EdgeTech sub-bottom data showed very little variation from two different returns: an acoustically transparent region, indicative of dense (hard) material mapped in the entrance channel and turning basin, and an acoustically opaque region, indicative of less dense (soft) sediment in the inner harbor and within Eighteenmile Creek proper (Figures 4, 6). A small region of more acoustically opaque data was also mapped in a small patch in the center of the channel, $\sim 260 \mathrm{ft}$ east of the turning basin. Along the harbor edges and within Eighteenmile Creek proper, SAV was apparent at the surface of the sediment and reflected back sufficient acoustic energy to both be visible in the sub-bottom record, as well as absorb some of the energy being output by the towfish (Figures 4,6 ).

Chirp sub-bottom data have the potential to image changes in density below the surface of the creek bed, yielding an estimate of sediment thickness. Of the 16 lines, 7 of them had limited sediment thickness, primarily at the start/end of the lines. The density variation was faint (see Figure 8 for an example), was noted anywhere between 2.5 and $5 \mathrm{ft}$ below the creek bed, and was limited to primarily next to the edges of the harbor and creek where the survey speed was the slowest. In addition, the faintness of the reflection surface indicates that the density change being mapped was very slight. Overall, the spatial limitations of these thicknesses precluded the generation of a robust, quantitative map for this region.

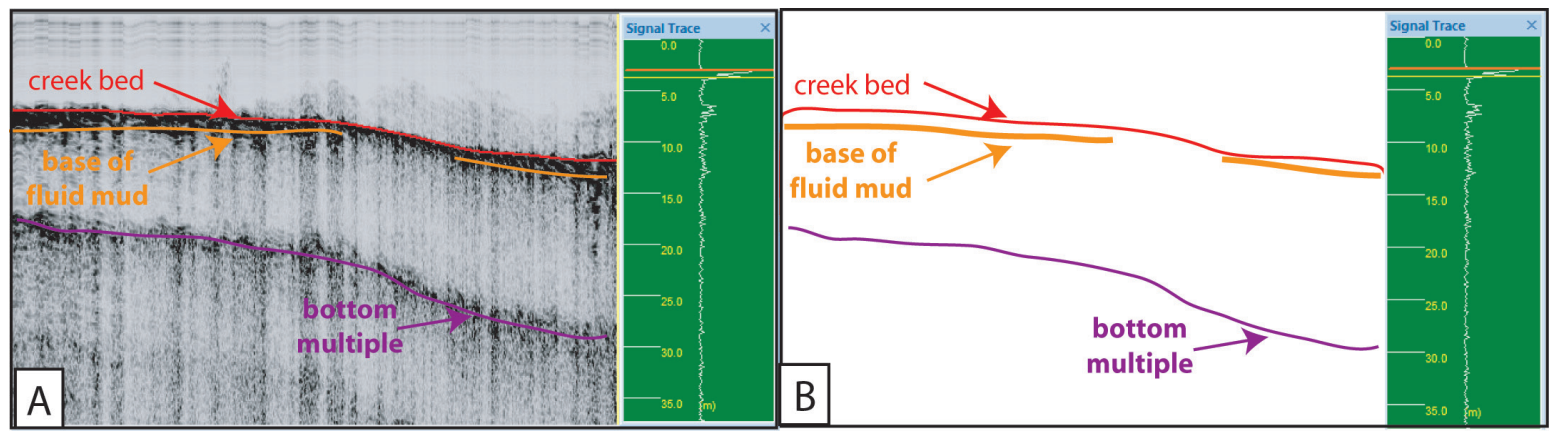

Figure 8. Thickness data shown on (A) an example sub-bottom profile; (B) stylized profile.

Unfortunately, the sub-bottom data recorded by the Kongsberg chirp towfish was of very limited use in this study. There was a significant amount of external noise in the data, likely due to the hydrophones being secured close to the towfish body and the vessel in order to safely tow the 
equipment in the limited harbor space. Of the four survey lines collected, only two provided any usable data. The lines do suggest a change in density from the outer to the inner harbor, as evidenced by a change in acoustic reflectance and the loss of an obvious data multiple commonly seen in denser sediments and restricted to the outer harbor only in these data. Thickness information for the main harbor could not be extracted from these data.

Of the seven surface grabs collected, three had a full grain-size analysis (ASTM D 422) performed by TTL Associates Inc, and the other four were given field classifications. A summary of the results is presented in Table 1, and the full quantitative analysis can be requested from the USACE LRB. The three samples analyzed by TTL Associates Inc. were dominantly fine grained, with EMC-03 \& EMC-01 containing the highest percentage of fine grained material $(78.8 \%$ and $60.7 \%$, respectively) and EMC-02 containing the least (18.4\%). EMC-02 was dominantly comprised of fine-grained sand with minor gravel (71.6\% vs. $10 \%$, respectively) and took four sampling attempts to gather sufficient material for quantitative analysis (a common problem when using a petit ponar to collect coarse-grained material). Accordingly, EMC-03 and EMC-01 were interpreted to be representative of fine-grained (muddy) regions, and EMC-02 was representative of coarse-grained regions. The other four samples were described in the field as dominantly muddy (including sufficient clay to cause the sediment to ribbon when smeared) or dominantly sand/gravel. Of those samples, EMC-04 and EMC-05 were coarse grained, and EMC-06 and EMC-07 were fine grained.

Table 1. Summary of grain-size data.

\begin{tabular}{|l|c|c|r|r|r|r|l||}
\hline \hline Sample ID & Latitude & Longitude & \% Gravel & \% Sand & \% Silt & \% Clay & \multicolumn{1}{|c||}{ Field ID } \\
\hline EMC-01 & $43^{\circ} 20.257^{\prime} \mathrm{N}$ & $78^{\circ} 43.025^{\prime} \mathrm{W}$ & $6.6 \%$ & $32.7 \%$ & $46.0 \%$ & $14.7 \%$ & Fine-grained \\
\hline EMC-02 & $43^{\circ} 20.245^{\prime} \mathrm{N}$ & $78^{\circ} 43.016^{\prime} \mathrm{W}$ & $10.0 \%$ & $71.6 \%$ & $12.7 \%$ & $5.7 \%$ & Coarse-grained \\
\hline EMC-03 & $43^{\circ} 20.171^{\prime} \mathrm{N}$ & $78^{\circ} 42.943^{\prime} \mathrm{W}$ & $4.0 \%$ & $20.8 \%$ & $51.4 \%$ & $27.4 \%$ & Fine-grained \\
\hline EMC-04 & $43^{\circ} 20.274^{\prime} \mathrm{N}$ & $78^{\circ} 43.065^{\prime} \mathrm{W}$ & -- & -- & -- & -- & Coarse-grained \\
\hline EMC-05 & $43^{\circ} 20.271^{\prime} \mathrm{N}$ & $78^{\circ} 43.116^{\prime} \mathrm{W}$ & -- & -- & -- & -- & Coarse-grained \\
\hline EMC-06 & $43^{\circ} 20.125^{\prime} \mathrm{N}$ & $78^{\circ} 42.947^{\prime} \mathrm{W}$ & -- & -- & -- & -- & Fine-grained \\
\hline EMC-07 & $43^{\circ} 20.102^{\prime} \mathrm{N}$ & $78^{\circ} 42.947^{\prime} \mathrm{W}$ & -- & -- & -- & -- & Fine-grained \\
\hline \hline
\end{tabular}

DISCUSSION: The sidescan, chirp sub-bottom, and grainsize data agree when defining the finegrained sediment in Eighteenmile Creek and Olcott Harbor. A total of 260,995 $\pm 5,220 \mathrm{ft}^{2}(\sim 6.0$ acres) of coarse-grained sediment was mapped at Olcott Harbor, and 187,058 $\pm 3,742 \mathrm{ft}^{2}(\sim 4.3$ acres) of fine-grained sediment was mapped in the harbor and the creek. Of the fine-grained region, $129,247 \pm 2585 \mathrm{ft}^{2} \quad(\sim 3$ acres) were dominantly SAV (and interpreted to be mud) while $57,811 \pm 1,156(\sim 1$ acre $)$ had little or no SAV on the surface. The primary sources of error in these measurements is due to (1) differential GPS horizontal positioning error (up to $6 \mathrm{~m}$ ) and (2) human error inherent in the digitization process (as calculated by comparing the deviation of repeated digitization efforts at the same location). Both errors average $\sim 0.2 \%$ in the horizontal dimension.

Fine-grained material (dominantly silt and clay) is limited to Eighteenmile Creek and the inner Olcott Harbor. There was slight, quantiative difference in acoustic amplitude between the finegrained sediment in the center of the harbor vs. that mapped along the edges that suggested the 
center sediments are slightly denser than those along the edges. This likely reflects a combination of factors, including slightly more wave energy reflected along the main channel from Lake Ontario and/or from passing vessels. Variations in wave energy would also explain the lack of fine-grained material or SAV in the outer harbor and turning basin.

Although nearly all of the inner harbor was fine grained, a small patch $(\sim 0.1$ acres $)$ of coarsegrained material was mapped just inside of the inner harbor, and this interpretation is supported by the quantitative grainsize percentage of EMC-02. This likely represents a region where large, wind-driven waves from Lake Ontario are reflected by the bulkhead along the edge of the outer harbor and turning basin and result in increased energy in that small region resuspending any finegrained sediment temporarily deposited there.

The paucity of lower reflection surfaces in this study area is due to several factors. In the outer harbor, wave energy likely suspends and transports any fine-grained sediment temporarily deposited within the region, allowing for preservation of only the coarse material. This winnowing results in a coarse-grained, armored surface that reflects most or all of the acoustic energy generated by the EdgeTech towfish. The result is a brighter region underneath the dense reflection surface, with few or no reflection surfaces visible below it (note the brighter region underlying the "coarse" region on Figure 5). This can be contrasted with softer sediment that often absorbs acoustic energy, resulting in no deeper returns as the energy is absorbed before it penetrates to lower layers (note the softer gray, "smudge" below the "fine-grained" region in Figure 5). A more powerful transducer might be able to penetrate the surficial sand layer, or penetrate deeper through the mud layer, but that was beyond the scope of this study and likely not necessary, as contaminants preferentially sorb to finer-grained particles.

In the inner harbor, the opposite problem occurred - the sediment density was low enough to absorb almost all of the acoustic energy generated by the EdgeTech towfish. The presences of abundant SAV growth contributed to this absorption. The limited reflection surfaces seen are likely the transition between more fluidized muds near the surface and denser, slightly dewatered mud below. This interpretation would explain why the sediment mapped in the channel of the creek and harbor was slightly denser in appearance, as it likely had significantly less fluid mud due to slightly higher wave energy. In addition, muddy sediment frequently contains free gas originating from the decay of organic matter. Gas has a pronounced effect on sediment acoustic properties, including reducing sediment strength and low-frequency sound speed, ultimately scattering acoustic energy (e.g., Davis 1992; Yuan et al. 1992; Lafferty et al. 2006). Seismic reflection amplitude data, representing variations in the strength of the returned acoustic signal, were used to discern if gas was significantly impacting sediment reflection in this region (e.g. MacDonald et al. 2003; Sager et al. 2003). Negative amplitudes indicate a decrease in sediment density (e.g., the presence of gas). Over $85 \%$ of the subbottom amplitude data was positive, suggesting that gas had a minimal effect on the chirp record. The EdgeTech $3100 \mathrm{p}$ is a high-frequency, lightweight system designed to be easily mobilized in the field. It is most likely that the small system simply lacked the power to transmit the acoustic signal through the SAV and mud. A different high-frequency towfish with a larger acoustic power capability might be able to better define this transition from fluid to more consolidated mud, as well as the thickness of the unit above the lower stratigraphic units in this area.

Despite these limitations, the limited thickness data suggests that the mud in these regions might be up to $5 \mathrm{ft}$ in thickness, though an average thickness of $\sim 3 \mathrm{ft}$ is more realistic. Extrapolated over 
the mapped regions, this suggests a volume of $561,174 \pm 11,224 \mathrm{ft}^{3}$ of fine-grained sediment might be contained within the Eighteenmile Creek and Olcott Harbor.

CONCLUSIONS: Overall, fine-grained sediment is restricted to inner Olcott Harbor and Eighteenmile Creek. Fine-grained sediment preserved along the center of the channel is more consolidated than that along the flanks and between the finger piers, and the distribution of SAV appears to follow the location of the acoustically less dense (e.g., fine-grained) sediment.

ADDITIONAL INFORMATION: This US Army Engineer Research and Development Center (ERDC) Coastal and Hydraulics Engineering Technical Note (ERDC-CHETN) was prepared as part of the USACE Dredging Operations Technical Support (DOTS) Program by Heidi M. Wadman, ERDC Coastal and Hydraulics Laboratory (CHL), Vicksburg, MS. Questions pertaining to this CHETN may be directed to Heidi Wadman (Heidi.M.Wadman@usace.army.mil); the USACE DOTS Program Manager is Dr. Burton Suedel (Burton.Suedel@usace.army.mil). Additional information regarding DOTS may be obtained from the DOTS website https://dots.el.erdc.dren.mil/.

This ERDC/CHL CHETN should be cited as follows:

Wadman, H. M. 2020. Fine-Grained Sediment within Olcott Harbor, Eighteenmile Creek, NY. ERDC/CHL CHETN-VII-23Vicksburg, MS: US Army Engineer Research and Development Center. http://dx.doi.org/10.21079/11681/37860

\section{REFERENCES}

Davis, A. M. 1992. "Shallow Gas: An Overview.” Continental Shelf Research 12(10): 1077-1079.

Lafferty, B., R. Quinn, and C. Breen. 2006. “A Side-Scan Sonar and High-Resolution CHIRP Sub-Bottom Profile Study of the Natural and Anthropogenic Sedimentary Record of Lower Lough Erne, Northwestern Ireland." Journal of Archaeological Science 33(6): 756-766.

MacDonald, I. R., W. W. Sager, and M. B. Peccini. 2003. "Gas Hydrate and Chemosynthetic Biota in Mounded Bathymetry at Mid-Slope Hydrocarbon Seeps: Northern Gulf of Mexico.” Marine Geology 198(1-2): 133158.

Sager, W. W., I. R. MacDonald, and R. Hou. 2003. "Geophysical Signatures of Mud Mounds at Hydrocarbon Seeps on the Louisiana Continental Slope, Northern Gulf of Mexico.” Marine Geology 198(1-2): 97-132.

Yuan, F., J. D. Bennell, and A. M. Davis. 1992. “Acoustic and Physical Characteristics of Gassy Sediments in the Western Irish Sea." Continental Shelf Research 12(10): 1121-1134. 
ERDC/CHL CHETN-VII-23

August 2020

\section{APPENDIX}

\begin{tabular}{|c|c|c|c|c|}
\hline \multicolumn{5}{|c|}{ Sub-Bottom Settings } \\
\hline Line Name & Equipment & Acquisition Settings & Import \% & Bottom Track \\
\hline PM_Chirp01 & LRE - Kongsberg & $9 \mathrm{Lin} ; 2-18 \mathrm{~Hz} ; \sin 2 ; 16 \mathrm{~ms}$ & $70 \%$ & --- \\
\hline PM_Chirp02 & LRE - Kongsberg & $\begin{array}{c}6 \mathrm{Lin} ; 1.5-13 \mathrm{~Hz} ; \sin 2 ; \\
16 \mathrm{~ms}\end{array}$ & $70 \%$ & --- \\
\hline Line_Grab01 & $\begin{array}{c}\text { LRB - EdgeTech } \\
3100 p\end{array}$ & $42.4-10 \mathrm{~Hz} ; 100 / 100$ & $50 \%$ & --- \\
\hline Line_Grab02 & $\begin{array}{c}\text { LRB - EdgeTech } \\
3100 p\end{array}$ & $42.4-10 \mathrm{~Hz} ; 100 / 100$ & $50 \%$ & --- \\
\hline Line_Grab03 & $\begin{array}{c}\text { LRB - EdgeTech } \\
3100 p\end{array}$ & $42.4-10 \mathrm{~Hz} ; 100 / 100$ & $50 \%$ & --- \\
\hline Line01 & $\begin{array}{c}\text { LRB - EdgeTech } \\
3100 p\end{array}$ & $42.4-5 \mathrm{~Hz} ; 100 / 100$ & $50 \%$ & --- \\
\hline Line02 & $\begin{array}{c}\text { LRB - EdgeTech } \\
3100 p\end{array}$ & $42.4-5 \mathrm{~Hz} ; 100 / 100$ & --- & --- \\
\hline Line03 & $\begin{array}{c}\text { LRB - EdgeTech } \\
3100 p\end{array}$ & $42.4-5 \mathrm{~Hz} ; 100 / 100$ & --- & --- \\
\hline Line04 & $\begin{array}{c}\text { LRB - EdgeTech } \\
3100 p\end{array}$ & $42.4-10 \mathrm{~Hz} ; 100 / 100$ & $50 \%$ & --- \\
\hline Line05 & $\begin{array}{c}\text { LRB - EdgeTech } \\
3100 p\end{array}$ & $42.4-10 \mathrm{~Hz} ; 100 / 100$ & $50 \%$ & --- \\
\hline Line06 & $\begin{array}{c}\text { LRB - EdgeTech } \\
3100 p\end{array}$ & $42.4-10 \mathrm{~Hz} ; 100 / 100$ & $50 \%$ & --- \\
\hline Line07 & $\begin{array}{c}\text { LRB - EdgeTech } \\
3100 p\end{array}$ & $42.4-10 \mathrm{~Hz} ; 100 / 100$ & $50 \%$ & --- \\
\hline Line08 & $\begin{array}{c}\text { LRB - EdgeTech } \\
3100 p\end{array}$ & $42.4-10 \mathrm{~Hz} ; 100 / 100$ & $50 \%$ & --- \\
\hline Line09 & $\begin{array}{c}\text { LRB - EdgeTech } \\
3100 p\end{array}$ & $42.4-10 \mathrm{~Hz} ; 100 / 100$ & $50 \%$ & --- \\
\hline Line10 & $\begin{array}{c}\text { LRB - EdgeTech } \\
3100 p\end{array}$ & $42.4-10 \mathrm{~Hz} ; 100 / 100$ & $50 \%$ & --- \\
\hline Line11 & $\begin{array}{c}\text { LRB - EdgeTech } \\
3100 p\end{array}$ & $42.4-10 \mathrm{~Hz} ; 100 / 100$ & $50 \%$ & --- \\
\hline Line12 & $\begin{array}{c}\text { LRB - EdgeTech } \\
3100 p\end{array}$ & $42.4-10 \mathrm{~Hz} ; 100 / 100$ & $50 \%$ & --- \\
\hline Line13 & $\begin{array}{c}\text { LRB - EdgeTech } \\
3100 p \\
\end{array}$ & $42.4-10 \mathrm{~Hz} ; 100 / 100$ & $50 \%$ & --- \\
\hline \multicolumn{5}{|c|}{ Sidescan Settings } \\
\hline Line Name & Equipment & Acquisition Settings & Import \% & Bottom Track \\
\hline Line_Grab01 & LRB - Starfish & --- & $70 \%$ & $\begin{array}{l}\text { blk2; dur4; thrsh80; } \\
\text { hand }\end{array}$ \\
\hline Line_Grab02 & LRB - Starfish & --- & $70 \%$ & --- \\
\hline
\end{tabular}




\begin{tabular}{|c|c|c|c|c||}
\hline Line_Grab03 & LRB - Starfish & -- & $70 \%$ & $\begin{array}{c}\text { blk2; dur4; thrsh80; } \\
\text { hand }\end{array}$ \\
\hline Line01 & LRB - Starfish & --- & $70 \%$ & $\begin{array}{c}\text { blk2; dur2; thrsh95; } \\
\text { hand }\end{array}$ \\
\hline Line02 & LRB - Starfish & --- & $70 \%$ & $\begin{array}{c}\text { blk2; dur2; thrsh95; } \\
\text { hand }\end{array}$ \\
\hline Line03 & LRB - Starfish & --- & $70 \%$ & $\begin{array}{c}\text { blk2; dur2; thrsh95; } \\
\text { hand }\end{array}$ \\
\hline Line04 & LRB - Starfish & --- & $70 \%$ & $\begin{array}{c}\text { blk2; dur2; thrsh95; } \\
\text { hand }\end{array}$ \\
\hline Line05 & LRB - Starfish & --- & $70 \%$ & $\begin{array}{c}\text { blk2; dur2; thrsh95; } \\
\text { hand }\end{array}$ \\
\hline Line06 & LRB - Starfish & --- & $70 \%$ & n/a - all by hand \\
\hline Line07 & LRB - Starfish & --- & $70 \%$ & $\begin{array}{c}\text { blk2; dur2; thrsh95; } \\
\text { hand }\end{array}$ \\
\hline Line08 & LRB - Starfish & --- & $70 \%$ & $\begin{array}{c}\text { blk2; dur2; thrsh95; } \\
\text { hand }\end{array}$ \\
\hline Line09 & LRB - Starfish & --- & $70 \%$ & n/a - all by hand \\
\hline Line10 & LRB - Starfish & --- & $70 \%$ & $\begin{array}{c}\text { blk2; dur2; thrsh95; } \\
\text { hand }\end{array}$ \\
\hline ine11 & LRB - Starfish & --- & $70 \%$ & n/a - all by hand \\
\hline Line12 & LRB - Starfish & --- & $\begin{array}{c}\text { blk2; dur2; thrsh95; } \\
\text { hand }\end{array}$ \\
\hline Line13 & LRB - Starfish & -- & $\begin{array}{c}\text { blk2; dur2; thrsh95; } \\
\text { hand }\end{array}$ \\
\hline \hline
\end{tabular}

NOTE: The contents of this technical note are not to be used for advertising, publication, or promotional purposes. Citation of trade names does not constitute an official endorsement or approval of the use of such products. 